\title{
Liposomal systems as carriers for bioactive compounds
}

\author{
Ana Maria Sper Simão ${ }^{1}$ Maytê Bolean ${ }^{1}$. Thuanny Alexandra Campos Cury ${ }^{1}$.

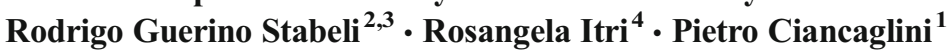

Received: 31 August 2015 / Accepted: 22 September 2015 /Published online: 10 October 2015

(C) International Union for Pure and Applied Biophysics (IUPAB) and Springer-Verlag Berlin Heidelberg 2015

\begin{abstract}
Since the revolutionary discovery that phospholipids can form closed bilayered structures in aqueous systems, the study of liposomes has become a very interesting area of research. The versatility and amazing biocompatibility of liposomes has resulted in their wide-spread use in many scientific fields, and many of their applications, especially in medicine, have yielded breakthroughs in recent decades. Specifically, their easy preparation and various structural aspects have given rise to broadly usable methodologies to internalize different compounds, with either lipophilic or hydrophilic properties. The study of compounds with potential biotechnological application(s) is generally related to evaluation and risk assessment of the possible cytotoxic or therapeutic effects of the compound under study. In most cases, undesirable sideeffects are associated with an interaction of the liposome with the cell membrane and/or its absorption and subsequent interaction with a cellular biomolecule. Liposomal carrier systems have an unprecedented potential for delivering bioactive substances to specific molecular targets due to their biocompatibility, biodegradability and low toxicity. Liposomes are
\end{abstract}

Pietro Ciancaglini

pietro@ffclrp.usp.br

1 Departmento de Química, Faculdade de Filosofia Ciências e Letras de Ribeirão Preto (FFCLRP), Universidade de São Paulo (USP), Av. Bandeirantes, 3900, 14040-901 Ribeirão Preto, SP, Brazil

2 Centro de Nanotecnologia Aplicada a Saúde-Nanosus, Presidência da Fiocruz, Rua Prof. Algacyr Munhoz Mader, 3775, 81350-010 Curitiba, PR, Brazil

3 Brasil e Universidade Federal de Rondônia, Porto Velho, Rondônia, Brazil

4 Depto. Física Aplicada, Instituto de Física, IF-USP, São Paulo, SP, Brazil therefore considered to be an invaluable asset in applied biotechnology studies due to their potential for interaction with both hydrophilic and lipophilic compounds.

Keywords Biotechnology $\cdot$ Carrier $\cdot$ Drugs $\cdot$ Liposome Delivery

\section{Liposomes}

Liposomes are spherical artificial lipid vesicles with an aqueous core enclosed by one or more lipid bilayers or lamellae, as first reported in 1964 (Bangham and Horne 1964). They are frequently classified on the basis of their size (small, large and giant vesicles), number of bilayers (uni-, oligo- and multilamellar) (Vuillemard 1991; Vemuri and Rhodes 1995) and phospholipid charge (neutral, anionic or cationic) (Storm and Crommelin 1998).

The properties of liposomes differ significantly depending on their lipid composition, surface charge, size and method of preparation. Thus, the choice of the lipid components determines the rigidity, fluidity and charge of the lipid bilayer and consequently the properties of the liposome. For example, the use of unsaturated species, such as phosphatidylcholines from natural sources (egg or soy phosphatidylcholines), results in the construction of relatively permeable liposomes, but with less stability, while saturated phospholipids with long acyl chains (e.g. dipalmitoyl phosphatidyl choline) form rigid vesicles, but with an impermeable bilayer (Akbarzadeh et al. 2013).

Multilamellar vesicles (MLVs) consist of several concentric phospholipid bilayers interspersed with aqueous compartments whose diameter ranges from 400 to $3500 \mathrm{~nm}$. Large unilamellar vesicles (LUVs) have a single phospholipid bilayer and only one large aqueous cavity with a diameter ranging 
from 200 to $1000 \mathrm{~nm}$. Small unilamellar vesicles (SUVs) are composed of only one phospholipid bilayer and a small aqueous compartment with a diameter ranging from 20 to $100 \mathrm{~nm}$ (Yeagle 1993; Akbarzadeh et al. 2013).

Among the various methods reported in the literature for liposome preparation, the most frequently used are lipid hydration, ethanol injection, freeze-thawing and reverse phase evaporation (Akbarzadeh et al. 2013; Patil and Jadhav 2014).

In the lipid hydration method, the lipid or lipid mixture is dissolved in an appropriate organic solvent (e.g. chloroform or methanol) followed by drying with a flow of an inert gas [e.g. nitrogen gas $\left(\mathrm{N}_{2}\right)$ ] to ensure complete removal of the solvent and formation of a thin lipid film. This film is hydrated with an aqueous buffer solution and heated at a temperature which is higher than the phase transition temperature of the lipid, with frequent stirring. After heating, the aqueous lipid suspension spontaneously organizes to form vesicles with multiple bilayers (multilamellar). This (re-)organization is driven by the entropy of water molecules and by hydrophobic interactions between the fatty acid chains of lipids.

Once formed, the multilamellar liposomes can be transformed into unilamillar vesicles by different methods (Zawada 2004; Akbarzadeh et al. 2013; Eloy et al. 2014; Madni et al. 2014). For example, MLVs may be sonicated or passed through a membrane with pores of nanometric dimensions (extrusion method) to form unilamellar vesicles that have properties very similar those of to natural membranes. Both the sonication and extrusion methods provide the energy required to break the various lamellae that initially formed and reorganize the system into uniform bilayers with controlled sizes of vesicles (Camolezi et al. 2002; Ierardi et al. 2002; Daghastanli et al. 2004; Santos et al. 2002, 2005; Rigos et al. 2008; dos Santos et al. 2009; Bolean et al. 2010, 2011; Simão et al. 2010a, b; Ciancaglini et al. 2012).

Sonication is probably the most widely used method for the preparation of SUVs and can be performed with a tip sonicator or bath sonicator. In the first case, the tip of the sonicator is dipped directly into the solution containing the SUVs, thereby providing very high energy to the lipid system, which can heat the solution. Thus, in order to avoid possible degradation of the lipids, it is necessary to maintain the lipid suspension in an ice bath during the sonication process or alternatively to use a bath sonicator which provides better control of the temperature of the lipid suspension during the process. The main disadvantages of this method are the formation of SUVs with their smaller aqueous cavity - and therefore smaller internal volume - resulting in a lower efficiency of encapsulation, possible degradation of the lipids and encapsulated compounds due to the temperature increase during the process, elimination of large molecules, contamination of the lipid solution with traces of metal (titanium) from the sonicator tip and the presence of MLVs formed together with SUVs (Akbarzadeh et al. 2013).
In the extrusion method, the multilamellar lipid suspension is forced under pressure through a membrane with pores of a predetermined diameters (nanometric scale). This process, as well as the method of freeze/thawing the lipid suspension, results in the formation of unilamellar vesicles which are larger than those formed by sonication; it also has a more accurate size control. The larger size is caused by the reduction of liposome lamellarity due to disruption of the bilayers, which then restructure to form new vesicles, thus increasing the number of vesicles and consequently encapsulation of the compound (Zawada 2004; Akbarzadeh et al. 2013; Eloy et al. 2014; Madni et al. 2014).

In the ethanol injection method, the lipid is first dissolved in ethanol and the solution then injected into an aqueous buffer. In the reverse phase evaporation method, a solution of the lipid and an organic solvent is added to an aqueous buffer solution to form a water-in-oil emulsion that is subjected to evaporation under low pressure, resulting in the formation of the liposome system (Madni et al. 2014).

In the freeze-thawing technique, the lipid film is hydrated with an aqueous buffer solution and subjected to repeated cycles of freezing/thawing, which cause physical disruption of the phospholipid bilayers due to the formation of ice crystals during the freezing process, thus increasing the aqueous solute/lipids ratio, resulting in a better carriage efficiency (Akbarzadeh et al. 2013; Eloy et al. 2014). Anzai et al. (1990) reported a ten- to fifty fold increase in the internal volume of the vesicles when the liposomal suspension was subjected to the freeze/thawing process. These authors suggested that the process induced the fusion of hundreds of small vesicles, which ultimately led to the formation of larger liposomes.

Many conventional methods for the preparation of liposomal vesicles involve the use of either water-miscible/-immiscible organic solvents or detergent molecules. Residual organic solvents may become toxic and degrade active ingredients, thus representing a possible risk to human health (Birnbaum et al. 2000). In the case of vesicles carrying proteins, organic solvents or detergents can denaturate the proteins and affect the membrane properties (Seddon et al. 2004), thus influencing the stability of vesicles (Wagner et al. 2002; Wagner and Vorauer-Uhl 2011; Patil and Jadhav 2014).

\section{Liposomal systems as carriers for bioactive compounds}

Liposomes were initially used as membrane models in biological studies. However, their cell-like structure led to investigations on their efficacy as a tool to carry potent molecules into the human body. Nowadays they are used for the encapsulation of unstable compounds considered to be essential to human health, such as antioxidants, antimicrobials, bioactive 
elements, antigenic proteins, thereby preserving their functionality (Madni et al. 2014; Schwendener 2014; Patil and Jadhav 2014). Liposomal vesicles have emerged as one of the novel carrier systems most studied by the scientific community over the past decades and have revolutionized research in many different fields, such as cosmetics, drugs, food, agriculture, with applications in chemotherapy treatments, gene therapy, vaccines, antimicrobial agents, among others (Madni et al. 2014).

The first report on the liposomal encapsulation of a therapeutic agent appeared in 1971 (Gregoriadis et al. 1971). A key advantage of liposomes in general, and liposomes-based delivery systems in particular, is their versatility and plasticity. The composition of the liposome and the method for its preparation can be chosen to achieve desired features, such as lipid composition and size, charge, size distribution and entrapment and location of different compounds. Depending on the chemical properties of the liposome, hydrophilic compounds (proteins, peptides, nucleic acids, carbohydrates) can be entrapped within the aqueous core, thereby increasing penetration of these compounds through physiological lipophilic membranes, whereas lipophilic compounds (linker molecules, antigens, adjuvants, lipopeptides) can be intercalated inside the lipid bilayer, thereby increasing their solubility in the aqueous body fluids (Fig. 1) (Rahman et al. 1974; Schwendener 2014).

The enormous versatility of liposomes makes them highly valuable carrier systems for vaccines. The liposome's ability to induce immune responses to incorporated or associated antigens was first reported by Allison and Gregoriadis (1974, 1976). Since then, liposomes and liposome-derived nanovesicles have become important carrier systems, and interest in developing liposome-based vaccines remains remarkably high. Antigens or adjuvants can be attached to the liposome surface either by adsorption or stable chemical linking (Torchilin 2005; Watson et al. 2012). Coformulations containing different types of adjuvants or antigens can be combined with specific liposome properties for the development of liposomal vaccines for individual applications (Schwendener 2014). Liposomes provide antigens or adjuvants with greater protection from external degradation caused by enzymes (Chaize et al. 2004), and because they are prepared from natural materials or their synthetic derivatives, they are biocompatible and biodegradable (Rooijen and Nieuwmegen 1980).

Depending on their specific properties of the carrier system, including size, composition and surface properties of the liposomes, these systems also possess the ability to overcome biological barriers, such as mucosa and skin, and they provide controlled and slow release of antigens, as well as improved antigen stability and presentation to immunocompetent cells. Together with the ability to induce strong immune responses provided by co-formulated adjuvants, liposome-based vaccines provide the fundamental properties required for the development of modern vaccine formulations (Schwendener 2014).

Immunoliposomes, which are formed from the conjugation of antibodies directly to the lipid bilayer of the liposome, are able to deliver the load specifically to the target tissues and safeguard other normal tissues from toxic effects. Liposomeencapsulated drugs have been shown to have a much higher efficacy than other conventional drug delivery systems. The main advantage of modern liposomes lies in their sustained
Fig. 1 Liposomal systems as carriers for bioactive compounds. Depending on the chemical properties, hydrophilic compounds are entrapped within the aqueous core of liposomes, whereas lipophilic compounds are intercalated inside the lipid bilayer. This feature makes it possible to produce liposomal systems with only one type of molecule incorporated, or more complex systems with different compounds encapsulated

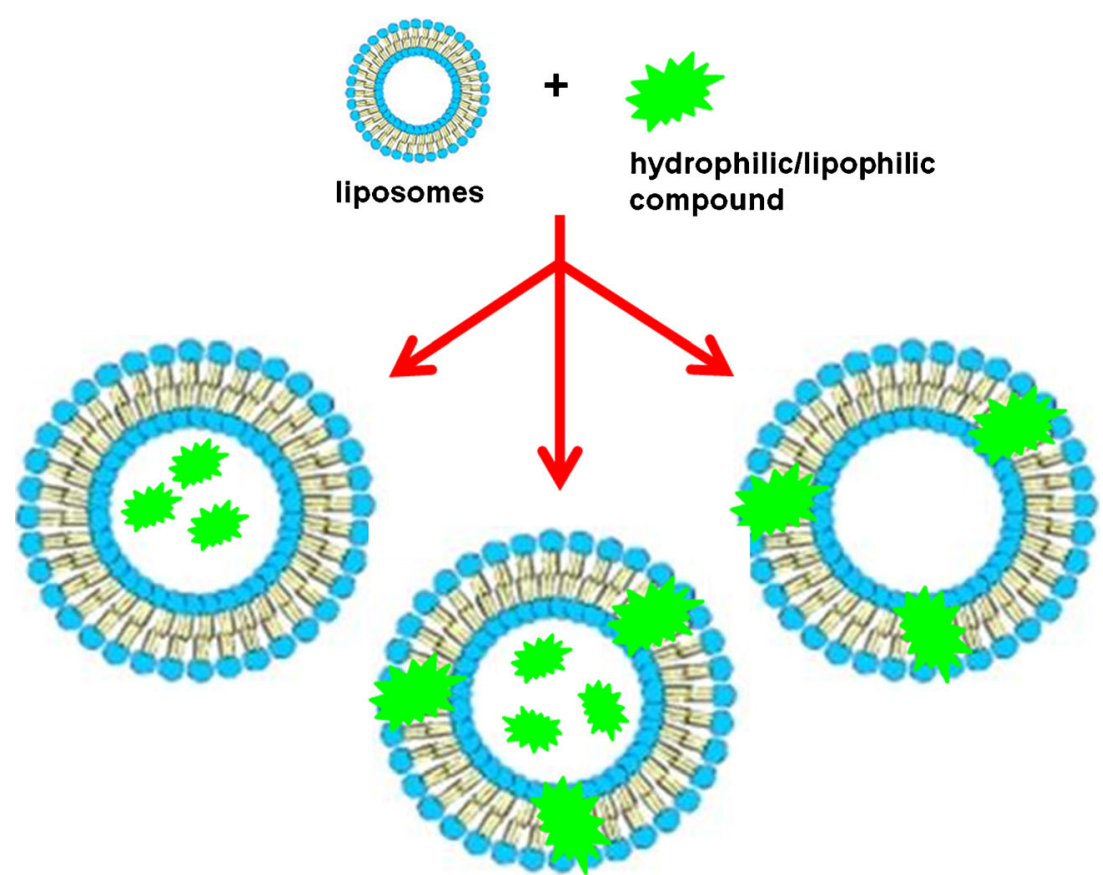


action, enhanced bioavailability, high cellular uptake and targeted delivery of therapeutic agents. It is predictable that these delivery systems will be increasingly applied in the near future with success, leading to major improvements in the field of vaccine development (Madni et al. 2014; Schwendener 2014).

Thus, liposomes are promising delivery systems mainly because of their biocompatibility, biodegradability and low toxicity in the human body (Benech et al. 2002; Saddi et al. 2008; Shehata et al. 2008; Akbarzadeh et al. 2013; Gao et al. 2014). Any compound, irrespective of its solubility, can be entrapped inside a liposome, resulting in a slow degradation during transport to the target, minimal side-effects and greater stability (Ghalandarlaki et al. 2014).

Despite the many advantages of using liposomes, including safety and biocompatibility, a major drawback is their instability in plasma. After intravenous administration, they are rapidly captured by the mononuclear phagocytic system (MPS) and removed from the blood circulation. This behavior has been explored for the efficient delivery of antiparasitic drugs for treating infections in these cells (Aqil et al. 2013). In this context, for example, plants from genus Piper have been investigated as a source of new natural products with potential antitumoral, antifungal, antiplasmodial, antioxidant and tripanocidal properties (da Silva et al. 2014), as well as antimicrobial, antipyretic, aromatic, emetic, diuretic, hallucinogen, ornamental and insect repellent roles, among other applications (Parmar et al. 1997; Wadt et al. 2004; Ferreira et al. 2010). Many components have been isolated from Piper plants, such as terpenes, phenylpropenoids, lignans, neolignans, steroids, benzopyrans, chalcones, flavones, other phenolic compounds and a series of alkaloids (Parmar et al. 1997; Wadt et al. 2004; Felipe et al. 2007).

Some species, such as P. chaba, P. claussenianum, $P$. longum, $P$. sanguineispicum and $P$. tuberculatum have shown antileishmanial activity due to the presence of compounds such as propanoic acid, lignans, terpenes, esters and amides (Carrara et al. 2013). The 3-(3,4,5-trimethoxyphenyl) propanoic acid extracted from $P$. tuberculatum Jacq. has been found to have potential leishmanicidal activity (Facundo et al. 2008; Ferreira et al. 2010; Barros et al. 2013). Leishmaniasis is endemic in more than 98 countries and territories. Not only do trusted treatments cause many side-effects in patients, but there is still the problem of parasites developing resistance to the drugs (Kaur and Rajput 2014). In addition, there is a lack of knowledge regarding the action mechanism of the drugs, and current treatment regimens are expensive (Alvar et al. 1997; Laguna et al. 2003; Chakravarty and Sundar 2010; Kaur and Rajput 2014).

In a recently published study, Cury et al. (2015) introduced synthetic analogs of 3-(3,4,5-trimethoxyphenyl) propanoic acid into liposomes and subsequently demonstrated their antileishmanial activity in cultures of Leishmania amazonensis promastigotes. The liposomal systems carrying the drugs were standardized, and the composition of the liposomes favored their interaction with the parasite cells. The compounds loaded into the liposomes led to an efficient reduction of the L. amazonensis culture at drug concentrations that were 20-, 40- and 100-fold lower than those used in the initial tests (with the drug dissolved in DMSO). Depending on the analog used, the carrier systems reduced the L. amazonensis culture by 50-80\%; the liposomes without drugs did not affect culture viability (Cury et al. 2015).

Liposomal systems have already been used to carry various compounds for the treatment of leishmaniasis, such as liposomal amphotericin B (AmBisome $\left.{ }^{\circledR}\right)$. This system has the potential to become a first-line drug in the treatment of visceral leishmaniasis (VL), but its high cost currently limits its use (Alvar et al. 1997; Laguna et al. 2003). This formulation also has a longer half-life time, which reduces the possibility of the emergence of resistance (Chakravarty and Sundar 2010). Studies in India have reported that a single dose of AmBisome $^{\circledR}$ is effective and safe for the treatment of VL, indicating that a reduced number of doses is efficacious, thereby reducing the costs of the treatment (Sundar et al. 2010).

Liposomal systems containing negative surface charges may result in a better delivery of drugs to the target cells. Akaki et al. (2001) evaluated the surface charges of infective forms of a number of parasites, including Leishmania, and observed that the parasites had positive charges in the membrane region which makes the initial contact with the host cells. Tempone et al. (2004) reported that negatively charged liposomes were efficient drug delivery systems to macrophages, inducing a decrease in Leishmania growth.

Barros et al. (2013) evaluated the antileishmanial activity of the lupane-triterpene $3 \beta, 6 \beta, 16 \beta$-trihydroxylup-20(29)ene, which has been shown to have various pharmacological properties (anti-inflammatory, anti-ulcerogenic and antileishmanial activities) when loaded into liposomes and delivered using this lyosome carrier system. These authors concluded that this lupane-liposomal system can be considered a promising therapeutic regimen, conferring antileishmanial activity to infected macrophages. Studies have shown that epiisopiloturine is potentiated and its antischistosomal effect prolonged when encapsulated into liposomes. These benefits can be attributed to the properties of extended delivery, with increased availability of the active principle (Guimarães et al. 2014).

The use of peptides as new drugs and insecticides is associated with both strengths and weaknesses. The peptides and proteins present in animal secretions and poisons have coevolved with their prey, or biological system, so that their mechanism of action is perfectly adapted. However, for biotechnological applications, they should be protected from hydrolysis and environmental changes, or even be preserved until they reach the specific target, in order to prevent any 
(adverse) reaction(s) other than the desired effect. Thus, active substances (from plants and/or animals) may be transported to specific molecular targets through nanostructured systems of natural or synthetic membranes, which can also preserve and increase the half life of the molecule (Salay et al. 2011; Barbosa et al. 2011).

The liposomal systems of SUVs also deserve attention as biosensing and delivery systems. Such systems can be used as biomimetic models for studies of interaction with various hydrophobic drugs and membrane proteins, with potential applications in the field of immunology (vaccines and drugs targeting specific cell membranes). Liposomes associated with proteins can be used to study the activity of photosensitive dyes applied during photodynamic therapy (Bolfarini et al. 2012; Longo et al. 2012; Rocha et al. 2012; Bicalho et al. 2013; Faria et al. 2015), as well for studies related to the ability of proteins to prevent, treat and/or act as nanosensors for various diseases (Daghastanli et al. 2004; Santos et al. 2006; Zucolotto et al. 2007; Migliaccio et al. 2008; Colhone et al. 2009, 2015; Calderon et al. 2009a, b; Perinoto et al. 2010; Paulovich et al. 2011; Barbosa et al. 2011; Salay et al. 2011; Barros et al. 2013; Fotoran et al. 2015).

Various types of liposomal delivery systems have been widely studied in recent years, in association with compounds for systemic and/or topical application in various therapeutic fields (e.g. cancer treatment, epilepsy, osteogenesis, treatment of viral and bacterial infections, among others) as well as for many other biomedical applications. These systems have very important physicochemical properties that can lead to highly optimized cell specificity, thus minimizing various limitations related to the administration of the drug alone. Their biological interaction is directly related to the chemical affinity for the delivery systems, which has led in recent years to the development of vehicles with greater biological potential as these favor higher biological uptake and are therefore associated with adequate pharmacokinetics. The attributes of liposomal delivery systems therefore minimize the side-effects usually present when many therapeutic drugs are used in their native therapeutic form, which can limit their applications.

\section{Conclusions}

Among the various benefits reported with the use of liposomal carrier systems, we highlight (1) the increased effectiveness of such therapies due to the gradual and controlled drug release through matrix degradation; (2) increased time of the drug in blood circulation; (3) significant reduction in toxicity of therapeutic regimens; (4) widely varying composition of the carriers; (5) ability to modify the carrier system to reduce its instability and drug decomposition (e.g. biological degradation by enzymes, $\mathrm{pH}$ and others). These features lead to a safer administration of the drug (e.g. without causing local inflammatory responses) and greater convenience to the patient (e.g. lower number of doses). The potential for drug targeting to specific targets is another advantage that has attracted the interest of researchers in various therapeutic fields. The potential for liposomes to combine with both hydrophilic and lipophilic compounds possibly extends the applications of liposomal systems and is a key reason motivating the development of this scientific field which is still underexplored.

Acknowledgments We thank Fundação de Amparo à Pesquisa do Estado de São Paulo (FAPESP), Coordenação de Aperfeiçoamento de Pessoal de Nível Superior (CAPES), and Conselho Nacional de Desenvolvimento Científico e Tecnológico $(\mathrm{CNPq})$ for the financial support given to our laboratory. PC, RGS and RI acknowledge CNPq for research fellowships.

\section{Compliance with Ethical Standards}

Declaration of conflict of interest The authors report that they have no conflict of interest to declare.

Ethical approval This article does not contain any studies with human or animal subjects performed by the authors.

\section{References}

Akaki M, Nakano Y, Nagayasu E, Nagakura K, Kawai S, Aikawa M (2001) Invasive forms of Toxoplasma gondii, Leishmania amazonensis and Trypanosoma cruzi have a positive charge at their contact site with host cells. Parasitol Res 87:193-197

Akbarzadeh A, Rezaei-Sadabady R, Davaran S, Joo SW, Zarghami N, Hanifehpour Y, Samiei M, Kouhi M, Nejati-Koshki K (2013) Liposome: classification, preparation, and applications. Nanoscale Res Lett 8:102

Allison A, Gregoriadis G (1974) Liposomes as immunological adjuvants. Nature 252:252

Allison AC, Gregoriadis G (1976) Liposomes as immunological adjuvants. Recent Results Cancer Res 56:58-64

Alvar J, Cañavate C, Solar BG, Jiménez M, Lagura F, Vélez R, Molina R, Moreno J (1997) Leishmania and human immunodeficiency virus coinfection: the first 10 years. Clin Microbiol Rev 10:298-319

Anzai K, Yoshida M, Kirino Y (1990) Change in intravesicular volume of liposomes by freeze-thaw treatment as studied. Biochim Biophys Acta 1021:21-26

Aqil F, Munagala R, Jeyabalan J, Vadhanam MV (2013) Bioavailability of phytochemicals and its enhancement by drug delivery systems. Cancer Lett 334:133-141

Bangham AD, Horne RW (1964) Negative staining of phospholipids and their structural modification by surface active agents as observed in the electron microscope. J Mol Biol 8:660-668

Barbosa SC, Cilli EM, Dias LG, Stabeli RG, Ciancaglini P (2011) Labaditin, a cyclic peptide with rich biotechnological potential: preliminary toxicological studies and structural changes in water and lipid membrane environment. Amino Acids 40:135-144

Barros NB, Migliaccio V, Facundo VA, Ciancaglini P, Stábeli RG, Nicolete R, Silva-Jardim I (2013) Liposomal-lupane system as alternative chemotherapy against cutaneous leishmaniasis: macrophage as target cell. Exp Parasitol 135:337-343 
Benech RO, Kheadr EE, Laridi R, Lacroix C, Fliss I (2002) Inhibition of Listeria innосиа in cheddar cheese by addition of nisin $\mathrm{Z}$ in liposomes or by in situ production in mixed culture. Appl Environ Microbiol 68:3683-3690

Bicalho LS, Longo JP, Cavalcanti CE, Simioni AR, Bocca AL, Santos MF, Tedesco AC, Azevedo RB (2013) Photodynamic therapy leads to complete remission of tongle tumor and inhibits metastases to region lymph nodes. J Biomed Nanotechnol 9:811-818

Birnbaum DT, Kosmala JD, Henthorn DB, Brannon-Peppas L (2000) Controlled release of $\beta$-estradiol from PLAGA microparticles: the effect of organic phase solvent on encapsulation and release. J Control Release 65:375-387

Bolean M, Simão AMS, Favarin BZ, Millán JL, Ciancaglini P (2010) The effect of cholesterol on the reconstitution of alkaline phosphatase into liposomes. Biophys Chem 152:74-79

Bolean M, Simão AMS, Favarin BZ, Millán JL, Ciancaglini P (2011) Thermodynamic properties and characterization of proteoliposomes rich in microdomains carrying alkaline phosphatase. Biophys Chem 158:111-118

Bolfarini GC, Siqueira-Moura MP, Demets GJ, Morais PC, Tedesco AC (2012) In vitro evaluation of combined hyperthermia and photodynamic effects using magnetoliposomes loaded with cucurbituril zinc phthalocyanine complex on melanoma. J Photochem Photobiol B 115:1-4

Calderon LA, Silva-Jardim I, Zuliani JP, Silva AA, Ciancaglini P, Silva LHP, Stábeli RG (2009a) Amazonian biodiversity: a view of drug development for leishmaniasis and malaria. J Braz Chem Soc 20: 1011-1023

Calderon LA, Messias MR, Serrano RP, Zaqueo KD, Souza ES, Nienow SS, Cardozo-Filho JL, Diniz-Sousa R, Delaix-Zaqueo K, Stábeli RG (2009b) Amphibia, Anura, Hylidae, Phyllomedusinae, Phyllomedusa azurea: distribution extension and geographic distribution map. Check List 5:317-319

Camolezi FL, Daghastanli KRP, Magalhães PP, Pizauro JM, Ciancaglini P (2002) Construction of an alkaline phosphatase-liposome system: a tool for biomineralization study. Int J Biochem Cell Biol 34:10911101

Carrara VS, Cunha-Júnior EF, Torres-Santos EC, Corrêa AG, Monteiro JL, Demarchi IG, Lonardoni MVC, Cortez DAG (2013) Antileishmanial activity of amides from Piper amalago and synthetic analogs. Rev Bras Farm 23:447-454

Chaize B, Colletier JP, Winterhalter M, Fournier D (2004) Encapsulation of enzymes in liposomes: high encapsulation efficiency and control of substrate permeability. Artif Cells Blood Substit Immobil Biotechnol 32:67-75

Chakravarty J, Sundar S (2010) Drug resistance in leishmaniasis. J Global Infect Dis 2:167-176

Ciancaglini P, Simão AMS, Bolean M, Millán JL, Rigos CF, Yoneda JS, Colhone MC, Stabeli RG (2012) Proteoliposomes in nanobiotechnology. Biophys Rev 4:67-81

Colhone MC, Nobre TM, Zaniquelli MED, Stabeli RG, Ciancaglini P (2009) Incorporation of antigenic GPI-proteins from Leishmania amazonensis in membrane mimetic systems: influence of DPPC/ cholesterol ratio. J Colloid Interface Sci 333:373-379

Colhone MC, Silva-Jardim I, Stabeli RG, Ciancaglini P (2015) Nanobiotechnologic approach to a promising vaccine prototype for immunization against leishmaniasis: a fast and effective method to incorporate GPI-anchored proteins of Leishmania amazonensis into liposomes. J Microencapsul 32:143-150

Cury TAC, Yoneda JS, Zuliani JP, Soares AM, Stábeli RG, Calderon LA, Ciancaglini P (2015) Cinnamic acid derived compounds loaded into liposomes: antileishmanial activity, production standardization and characterization. J Microencapsul 32:467-477

da Silva JKR, Pinto LC, Burbano RMR, Montenegro RC, Guimarães EF, Andrade EHA, Maia JGS (2014) Essential oils of Amazon Piper species and their cytotoxic, antifungal, antioxidant and anticholinesterase activities. Ind Crops Prod 58:55-60

Daghastanli KRP, Ferreira RB, Thedei G Jr, Maggio B, Ciancaglini P (2004) Lipid composition-dependent incorporation of multiple membrane proteins into liposomes. Colloids Surf B: Biointerfaces 36:127-137

dos Santos LER, Colhone MC, Daghastanli KRP, Stabeli RG, SilvaJardim I, Ciancaglini P (2009) Lipid microspheres loaded with antigenic membrane proteins of the Leishmania amazonensis as a potential biotechnology application. J Colloid Interface Sci 340:112118

Eloy JO, Claro de Souza M, Petrilli R, Barcellos JP, Lee RJ, Marchetti JM (2014) Liposomes as carriers of hydrophilic small molecule drugs: strategies to enhance encapsulation and delivery. Colloids Surf B: Biointerfaces 123C:345-363

Facundo VA, Polli AR, Rodrigues RV, Militão JSLT, Stabelli RG, Cardoso CT (2008) Fixed and volatile chemical constituents from stems and fruits of Piper tuberculatum Jacq. and from roots of P. hispidum. Acta Amazon 38:743-748

Faria PE, Felipucci DN, Simioni AR, Primo FL, Tedesco AC, Salata LA (2015) Effects of photodynamic process (PDP) in implant osseointegration: a histologic and histometric study in dogs. Clin Implant Dent Relat Res 17:879-890

Felipe FCB, Filho JTS, Souza LEO, Silveira JA, Uchoa DEA, Silveira ER, Pessoa ODL, Viana GSB (2007) Piplartine, an amide alkaloid from Piper tuberculatum, presents anxiolytic and antidepressant effects in mice. Phytomedicine 14:605-612

Ferreira MGPR, Kayano AM, Jardim IS, Silva TO, Zuliani JP, Facundo VA, Calderon LA, Silva AA, Ciancaglini P, Stábeli RG (2010) Antileishmanial activity of 3-(3,4,5-trimethoxyphenyl) propanoic acid purified from Amazonian Piper tuberculatum Jacq., Piperaceae, fruits. Braz J Pharmacog 20:1003-1006

Fotoran WL, Santangelo RM, Medeiros MM, Colhone MC, Ciancaglini P, Barboza R, Marinho CR, Stábeli RG, Wunderlich G (2015) Liposomes loaded with $\mathrm{P}$. falciparum merozoite-derived proteins are highly immunogenic and produce invasion-inhibiting and antitoxin antibodies. J Control Release 217:121-127

Gao W, Thamphiwatana S, Angsantikul P, Zhang L (2014) Nanoparticle approaches against bacterial infections. Wiley Interdiscip Rev Nanomed Nanobiotechnol 6:532-547

Ghalandarlaki N, Alizadeh AM, Ashkani-Esfahani S (2014) Nanotechnology-applied curcumin for different diseases therapy. Biomed Res Int 2014:394264

Gregoriadis G, Leathwood PD, Ryman BE (1971) Enzyme entrapment in liposomes. FEBS Lett 14:95-99

Guimarães MA, Campelo YD, Véras LM, Colhone MC, Lima DF, Ciancaglini P, Kuckelhaus SS, Lima FC, de Moraes J, de Leite JR (2014) Nanopharmaceutical approach of epiisopiloturine alkaloid carried in liposome system: preparation and in vitro schistosomicidal activity. J Nanosci Nanotechnol 14:4519-4528

Ierardi DF, Pizauro JM, Ciancaglini P (2002) Erythrocyte ghost cellalkaline phosphatase: construction and characterization of a vesicular system for use in biomineralization studies. Biochim Biophys Acta 1567:183-192

Kaur G, Rajput B (2014) Comparative analysis of the omics technologies used to study antimonial, amphotericin B, and pentamidine resistance in Leishmania. J Parasitol Res. doi:10.1155/2014/726328

Laguna F, Videla S, Jiménez-Mejías ME, Sirera G, Torre-Cisneros J, Ribera E, Prados D, Clotet B, Sust M, López-Vélez R, Alvar J (2003) Spanish HIV-Leishmania Study Group. Amphotericin B lipid complex versus meglumine antimoniate in the treatment of visceral leishmaniasis in patients infected with HIV: a randomized pilot study. J Antimicrob Chemother 52:464-468

Longo JP, Leal SC, Simioni AR, de Fátima MAS, Tedesco AC, Azevedo RB (2012) Photodynamic therapy disinfection of carious tissue mediated by aluminum-chloride-phthalocyanine entrapped in cationic 
liposomes: an in vitro and clinical study. Lasers Med Sci 27:575584

Madni A, Sarfraz M, Rehman M, Ahmad M, Akhtar N, Ahmad S, Tahir N, Ijaz S, Al-Kassas R, Löbenberg R (2014) Liposomal drug delivery: a versatile platform for challenging clinical applications. J Pharm Pharm Sci 17:401-426

Migliaccio V, Santos FR, Ciancaglini P, Ramalho-Pinto FJ (2008) Use of proteoliposome as a vaccine against Trypanosoma cruzi in mice. Chem Phys Lipids 152:86-94

Parmar VS, Jain SC, Bisht KS, Jain R, Taneja P, Jha A, Tyagi OD, Prasad AK, Wengel J, Olsen CE, Boll PM (1997) Phytochemistry of the genus Piper. Phytochemistry 46:597-673

Patil YP, Jadhav S (2014) Novel methods for liposome preparation. Chem Phys Lipids 177:8-18

Paulovich FV, Maki RM, de Oliveira MCF, Colhone MC, Santos FR, Migliaccio V, Ciancaglini P, Daghastanli KR, Stabeli RG, Perinoto AC, Oliveira ON Jr, Zucolotto V (2011) Using multidimensional projection techniques for reaching a high distinguishing ability in biosensing. Anal Bioanal Chem 400:1153-1159

Perinoto AC, Maki RM, Colhone MC, Santos FR, Migliaccio V, Daghastanli KR, Stabeli RG, Ciancaglini P, Paulovich FV, de Oliveira MCF, Oliveira ON Jr, Zucolotto V (2010) Biosensors for efficient diagnosis of leishmaniasis: innovations in bioanalytics for a neglected disease. Anal Chem 82:9763-9768

Rahman YE, Rosenthal MW, Cerny EA, Moretti ES (1974) Preparation and prolonged tissue retention of liposome encapsulated chelating agents. J Lab Clin Med 83:640-647

Rigos CF, Nobre TM, Zaniquelli MED, Ward RJ, Ciancaglini P (2008) The association of Na, K-ATPase subunits studied by circular dichroism, surface tension and dilatational elasticity. J Colloid Interface Sci 325:478-484

Rocha MS, Lucci CM, Longo JP, Galera PD, Simioni AR, Lacava ZG, Tedesco AC, Azevedo RB (2012) Aluminum-chloridephthalocyanine encapsulated in liposomes: activity against naturally occurring dog breast cancer cells. J Biomed Nanotechnol 8:251-257

Rooijen N, Nieuwmegen R (1980) Liposomes in immunology: multilamellar phosphatidylcholine liposome as a simple biodegradable and harmless adjuvant without any immunogenic activity of its own. Immunol Commun 9:243-256

Saddi KR, Alves GD, Paulino TP, Ciancaglini P, Alves JB (2008) Epidermal growth factor in liposomes may enhance osteoclast recruitment during tooth movement in rats. Angle Orthod 78:604-609

Salay LC, Nobre TM, Colhone MC, Zaniquelli MED, Ciancaglini P, Stabeli RG, Leite JRSA, Zucolotto V (2011) Dermaseptin 01 as antimicrobial peptide with rich biotechnological potential: study of peptide interaction with membranes containing Leishmania amazonensis lipid-rich extract and membrane models. J Pept Sci 17:700-707

Santos HL, Lamas RP, Ciancaglini P (2002) Solubilization of Na, KATPase from outer medulla of rabbit kidney using only C12E8. Braz J Med Biol Res 35:277-288

Santos HL, Lopes ML, Maggio B, Ciancaglini P (2005) Na, K-ATPase reconstituted in liposomes: effects of lipid composition on hydrolytic activity and enzyme orientation. Colloids Surf B: Biointerfaces 41:239-248
Santos FR, Ferraz DB, Daghastanli KRP, Ramalho-Pinto FJ, Ciancaglini P (2006) Mimetic membrane system to carry multiple antigenic proteins from Leishmania amazonensis. J Membr Biol 210:173-181

Schwendener RA (2014) Liposomes as vaccine delivery systems: a review of the recent advances. Ther Adv Vaccines 2:159-182

Seddon AM, Curnow P, Booth PJ (2004) Membrane proteins, lipids and detergents: not just a soap opera. Biochim Biophys Acta 1666:105117

Shehata T, Ogawara K, Higaki K, Kimura T (2008) Prolongation of residence time of liposome by surface-modification with mixture of hydrophilic polymers. Int J Pharm 359:272-279

Simão AMS, Ciancaglini P, Yadav MC, Narisawa S, Bolean M, Pizauro JM, Hoylaerts MF, Millán JL (2010a) Proteoliposomes harboring alkaline phosphatase and nucleotide pyrophosphatase as matrix vesicles' biomimetics. J Biol Chem 285:7598-7609

Simão AMS, Yadav MC, Ciancaglini P, Millán JL (2010b) Proteoliposomes as matrix vesicles' biomimetics to study the initiation of skeletal mineralization. Braz J Med Biol Res 43:234-241

Storm G, Crommelin DJA (1998) Liposomes: quo vadis? Pharm Sci Technol Today 1:19-31

Sundar S, Chakravarty J, Agarwal D, Rai M, Murray HW (2010) Singledose liposomal amphotericin B for visceral leishmaniasis in India. $\mathrm{N}$ Engl J Med 362:504-512

Tempone AG, Perez D, Rath S, Vilarinho AL, Mortara RA, de Andrade HF Jr (2004) Targeting Leishmania (L.) chagasi amastigotes through macrophage scavenger receptors: the use of drugs entrapped in liposomes containing phosphatidylserine. J Antimicrob Chemother 54:60-68

Torchilin VP (2005) Recent advances with liposomes as pharmaceutical carriers. Nat Rev Drug Discov 4:145-160

Vemuri S, Rhodes CT (1995) Preparation and characterization of liposomes as therapeutic delivery systems: a review. Pharm Acta Helv 70:95-111

Vuillemard JC (1991) Recent advances in the large-scale production of lipid vesicles for use in food products: microfluidization. J Microencapsul 8:547-562

Wadt LHO, Ehringhaus C, Kageyama PY (2004) Genetic diversity of "Pimenta Longa" genotypes (Piper spp., Piperaceae) of the Embrapa Acre germplasm collection. Genet Mol Biol 27:74-82

Wagner A, Vorauer-Uhl K (2011) Liposome technology for industrial purposes. J Drug Deliv 2011:591325

Wagner A, Vorauer-Uhl K, Katinger H (2002) Liposomes produced in a pilot scale: production, purification and efficiency aspects. Eur J Pharm Biopharm 54:213-219

Watson D, Endsley A, Huang L (2012) Design considerations for liposomal vaccines: influence of formulation parameters on antibody and cell-mediated immune responses to liposome associated antigens. Vaccine 30:2256-2272

Yeagle PL (1993) The membranes of cells, 2nd edn. Academic Press, New York

Zawada Z (2004) A single-step method of liposome preparation. Cell Mol Biol Lett 9:603-615

Zucolotto V, Daghastanli KRP, Hayasaka CO, Riul A Jr, Ciancaglini P, Oliveira ON Jr (2007) Using capacitance measurements as the detection method in antigen-containing layer-by-layer films for biosensing. Anal Chem 79:2163-2167 